Expert Advisory Panel on Drug Dependence and Alcohol Problems from 1977 to 1998 and as a member of the Expert Advisory Panel on Drug Dependence (Dependence Liability) since 1998. He served on several Expert Committees, including the 33rd and 34th Expert Committees on Drug Dependence. Dr Schuster also founded the University of Chicago's Drug Abuse Research Center. From 1986 to 1992, he served as the Director of the National Institute on Drug Abuse, a position from which he oversaw the development of grant and contract programmes to fund research into the aetiology, prevention and treatment of drug misuse, and its medical and social consequences. In 2000, he became Director of the Addiction Research Institute at Wayne State University, a position he held until his premature death. Dr Schuster made an outstanding international contribution to the field of addictions and international drug policy. He was a visionary leader with great personal charm, charisma and empathy for people in distress, whether through addictions or other mental illness. Deepest condolences go to his family and friends.

\section{NHS reforms - a threat to mental health services?}

\begin{abstract}
C. As a psychiatrist and general practitioner (GP) who moved to the UK to train in the National Health Service (NHS), we are concerned that controversial proposals for wide-sweeping reform may damage mental healthcare provision. According to a Department of Health spokesman (as widely reported in the news media, 11 March 2011), the UK government proposes to 'cut bureaucracy and give doctors the power and freedom to make the service more responsive to patient needs'. general practitioners are to be handed budgets to commission specialist services, including mental health services, with an emphasis on competition, not collaboration. We are concerned that these reforms are another step towards the privatisation of the NHS. Experience in countries with private, competitive healthcare systems is that mental health service users may be at a disadvantage and the quality of care variable. Recent US healthcare reforms towards a more inclusive model, based on social care and supporting the more vulnerable in society, reinforce this view.
\end{abstract}

The evidence for the need for transformation has been on the basis of poorer health outcomes in the UK compared with countries with similar levels of spending on health. This evidence has been contested robustly (Appleby, 2011; Goldacre, 2011). Moreover, the British Medical Association has stated that the reforms are 'potentially damaging' (as reported on 1 October 2010), particularly where competition as opposed to collaboration risks fragmentation of services.

The implications for mental health services are unclear. However, a number of UK mental health groups have expressed disquiet at the potential effects of these proposals. A survey by the charity Rethink (2010) found that most GPs did not feel equipped to commission mental health services. The mental health charity Mind (2011) has called on the UK government to ensure that any changes to NHS commissioning do not jeopardise the continuity and quality of care currently received by people with mental health problems. It emphasised the difficulties people already face in a relatively well provisioned NHS mental health service. Mind (2011) also raised the spectre of GP 'doorstep lobbying', which may mean that mental health loses out in the battle for resources. A study by the Institute for Public Policy Resource Research (2011) suggested that the quality of dementia care would suffer under the reforms. The Institute reported that just $31 \%$ of GPs in London feel that they have received sufficient training to diagnose dementia. Furthermore, productivity improvements could be put at risk by the reforms, as could joint working, according to a report by the King's Fund and the Centre for Mental Health, with input from the Royal College of Psychiatrists and other stakeholders (see King's Fund, 2010). Substantial long-term financial savings can be made by integrating mental health and social care services according the King's Fund study.

It is difficult to see how the proposals in their current form might promote integration and collaboration when their focus is on competition and fragmentation. Collaborative working across and between services, and optimal care pathways, are a cornerstone of successful mental health service provision. Countries undergoing healthcare reform might wish to follow both developments and mental health outcomes in the UK over the next few years.

Gregory Lydall ${ }^{1}$ and Maatje P. Du Plessis ${ }^{2}$ Consultant Psychiatrist, Guernsey; ${ }^{2}$ GP, London

Appleby, J. (2011) Does poor health justify NHS reform? BMJ, 342, d566. Goldacre, B. (2011) Evidence supporting your NHS reforms? What evidence, Mr Lansley? Guardian, 5 February.

Institute for Public Policy Resource Research (2011) Dementia care would suffer under government's NHS reforms. Press release. Available at http://ippr.org.uk/articles/?id=4400 (accessed March 2011).

King's Fund (2010) Radical changes to mental health services needed to cut costs and improve patient care, says new report. Press release. Available at http://www.kingsfund.org.uk/press/press_releases/radical_ changes_to_1.html (accessed March 2011).

Mind (2011) NHS reforms must not threaten continuity and quality of mental health services. Press release. Available at http://www.mind. org.uk/news/4471_nhs_reforms_must_not_threaten_continuity_and_ quality_of_mental_health_services (accessed March 2011).

Rethink (2010) White paper to hand mental health commissioning to GPs but most don't have necessary expertise. Press release. Available at http://www.rethink.org/how_we_can_help/news_and_media/press releases/white_paper_to_hand.h̄tml (accessed March 2011). 